\title{
Preimplantation Genetic Testing for Inherited Predisposition to Cardiac Disease
}

\author{
Anver Kuliev", Tatiana Pakhalchuk, Maria Prokhorovich and Svetlana Rechitsky \\ Reproductive Genetic Innovations, USA
}

\begin{abstract}
Summary
Cardiac disease, which is a common condition with genetic predisposition, has become a relatively frequent indication for preimplantation genetic testing (PGT), performed in the last dozen years to provide an option for couplers at risk to avoid the birth of an offspring without predisposition to cardiac disease. We present here our experience of 109 PGT cycles for cardiac disease, resulting in birth of 54 mutation free children, which is a part of our overall PGT series of 6204 PGT cycles for monogenic disorders (PGT-M), with 2,517 resulting births, free of genetic disorders. The accumulated experience, presented below, demonstrates considerable progress in using PGT for avoiding the birth of children with genetic predisposition to cardiac disease.
\end{abstract}

\section{Introduction}

At the present time there is no appropriate strategies to prevent the realization of cardiac disease in the carries of gene mutations predisposing to this condition, so avoiding the birth of such offspring is becoming quite attractive to couples at risk, through the option of preimplantation genetic testing (PGT), currently performed for increasing number of patients [1-4]. The available framework of avoiding the birth of affected children involves an expanding carrier screening for identification of individuals at risk, providing them with an option of avoiding the birth of a child with predisposition to cardiac disease, and, instead, to have an offspring free from the genes predisposing to the disease by utilizing of PGT.

Accordingly, it is reasonable that this information should be available to the couples, with family history of cardiac disease, so they could make their choices for carrier screening and PGT. Thus, this paper will describe the present status of PGT for cardiac disease, as an approach for avoiding the birth of children at risk for developing such condition, based on our experience since we described the first series of PGT for cardiac disease in 2012 [2].

\section{Material and Methods}

A total of 109 PGT cycles for 67 couples (Table 1) at risk for producing a progeny with mutations predisposing to cardiac disease were performed (list of mutations for which PGT was performed is presented in Table 2). The most frequent were hypertrophic cardiomyopathy, $\mathrm{CMH} 4$, caused by $M Y B S P C 3$ mutation (22 cycles performed for 14 patients), and dilated cardiomyopathy, CMD1A, caused by LMNA gene mutation (17 cycles performed for 7 patients). PGT for remaining mutations were performed in 8 or less cycles.
PGT cycles were performed using a standard IVF protocol, coupled with micromanipulation procedures of polar bodies (PB) or embryo biopsy, described in detail elsewhere [5]. Details of PGT guidelines were reported previously [6-7]. The present standards of the procedure involve whole genome amplification (WGA) of biopsied PBs or embryos biopsy samples, followed by multiplex nested PCR analysis of the mutations in question, together with closely linked genetic markers in a multiplex hemi nested system. The majority of cases are currently performed by blastocyst biopsy followed by WGA $[5,8]$. For each family, heterozygous alleles and haplotypes not shared by parents were selected. This allowed detecting and avoiding misdiagnosis due to preferential amplification and allele dropout (ADO), and a possible aneuploidy or uniparental disomy of chromosomes in which the tested mutations are located, which may affect diagnostic accuracy of PGT. In PGT cycles, involving an advanced reproductive age of maternal partner, aneuploidy testing was also performed by next generation technologies (NGS) (Illumina Inc) for 24-chromosome aneuploidy testing $[5,8]$.

\section{Results and Discussion}

Table 1 presents our cumulative experience of 109 PGT

*Corresponding author: Anver Kuliev, Reproductive Genetic Innovations, 2910 MacArthur Blvd, Chicago, IL 60062, USA

Accepted: February 13, 2021

Published online: February 15, 2021

Citation: Kuliev A, Pakhalchuk T, Prokhorovich M, et al. (2021) Preimplantation Genetic Testing for Inherited Predisposition to Cardiac Disease. Ann Heart 5(1):96-99 
Citation: Kuliev A, Pakhalchuk T, Prokhorovich M, et al. (2021) Preimplantation Genetic Testing for Inherited Predisposition to Cardiac Disease. Ann Heart 5(1):96-99

Table 1: PGT for Cardiac diseases in our overall PGT-M experience.

\begin{tabular}{|c|c|c|c|c|c|c|}
\hline Disease & Gene & \# Cycle & \# Transfers & $\begin{array}{l}\text { \# Embryos } \\
\text { transferred }\end{array}$ & Pregnancy & Birth \\
\hline $\begin{array}{l}\text { Acyl-CoA Dehydrogenase, VERY LONG-CHAIN, DEFICIENCY } \\
\text { OF; ACADVLD }\end{array}$ & $A C A D V L(A R)$ & 6 & 8 & 12 & 2 & 2 \\
\hline $\begin{array}{l}\text { CARDIOENCEPHALOMYOPATHY, FATAL INFANTILE, DUE TO } \\
\text { CYTOCHROME C OXIDASE DEFICIENCY 1; CEMCOX1 }\end{array}$ & $S C O 2(A R)$ & 5 & 5 & 10 & 3 & 3 \\
\hline CARDIOFACIOCUTANEOUS SYNDROME 4; CFC4 & $M A P 2 K 2(A D)$ & 2 & 1 & 1 & 1 & 1 \\
\hline CARDIOMYOPATHY, DILATED, 1A; CMD1A & LMNA (AD) & 17 & 15 & 24 & 9 & 10 \\
\hline CARDIOMYOPATHY, DILATED, 1DD; CMD1DD & RBM20 (AD) & 2 & 3 & 3 & 2 & 2 \\
\hline CARDIOMYOPATHY, DILATED, 1E; CMD1E & $S C N 5 A(A D)$ & 2 & 2 & 2 & 1 & 1 \\
\hline CARDIOMYOPATHY, DILATED, 1G; CMD1G & $\operatorname{TTN}(A D)$ & 1 & 1 & 1 & 1 & 1 \\
\hline $\begin{array}{l}\text { CARDIOMYOPATHY, DILATED, WITH WOOLLY HAIR, } \\
\text { KERATODERMA, AND TOOTH AGENESIS; DCWHKTA }\end{array}$ & $D S P(A D)$ & 3 & 2 & 2 & 2 & 1 \\
\hline CARDIOMYOPATHY, FAMILIAL HYPERTROPHIC, 1; CMH1 & $M Y H 7(A D)$ & 6 & 4 & 4 & 2 & 2 \\
\hline CARDIOMYOPATHY, FAMILIAL HYPERTROPHIC, 2; CMH2 & TNNT2 (AD) & 1 & 1 & 2 & 1 & 2 \\
\hline CARDIOMYOPATHY, FAMILIAL HYPERTROPHIC, 4; CMH4 & MYBPC3 (AD) & 22 & 16 & 23 & 11 & 9 \\
\hline CARDIOMYOPATHY, FAMILIAL HYPERTROPHIC, 7; CMH7 & TNNI3 (AD) & 1 & 1 & 1 & 0 & 0 \\
\hline CARDIOMYOPATHY, FAMILIAL HYPERTROPHIC, 8; CMH8 & $M Y L 3(A D)$ & 2 & 1 & 1 & 0 & 0 \\
\hline $\begin{array}{l}\text { CARDIO SKELETAL MYOPATHY WITH NEUTROGENA AND } \\
\text { ABNORMAL MITOCHONDRIA }\end{array}$ & $T A Z(X L R)$ & 1 & 1 & 1 & 1 & 1 \\
\hline COENZYME Q10 DEFICIENCY, PRIMARY, 7; COQ10D7 & COQ4 (AR) & 1 & 1 & 1 & 1 & 1 \\
\hline $\begin{array}{l}\text { EMERY-DREIFUSS MUSCULAR DYSTROPHY 1, X-LINKED; } \\
\text { EDMD1 }\end{array}$ & $E M D(X L R)$ & 4 & 4 & 6 & 3 & 3 \\
\hline HOLT-ORAM SYNDROME; HOS & $T B \times 5(A D)$ & 8 & 7 & 8 & 3 & 4 \\
\hline LOEYS-DIETZ SYNDROME 1; LDS1 & TGFBR2 (AD) & 5 & 4 & 6 & 2 & 1 \\
\hline LONG QT SYNDROME 1; LQT1 & KCNQ1 (AD) & 6 & 3 & 3 & 3 & 3 \\
\hline LONG QT SYNDROME 2; LQT2 & KCNH2 (AD) & 3 & 1 & 1 & 1 & 1 \\
\hline LONG QT SYNDROME 8; LQT8 & CACNA1C (AD) & 1 & 1 & 1 & 1 & 1 \\
\hline MYOPATHY, MYOFIBRILLAR, 1; MFM1 & $D E S(A D)$ & 2 & 2 & 3 & 1 & 1 \\
\hline NOONAN SYNDROME 1; NS1 & PTPN11 (AD) & 8 & 5 & 7 & 4 & 4 \\
\hline Total PGT for Cardiac disease & 23 GENES & 109 & 89 & $123(1.38)$ & $55(61.7 \%)$ & 54 \\
\hline Total PGT-M Experience & 558 GENES & 6204 & 4630 & 70611.52 & $244752.80 \%$ & 2517 \\
\hline
\end{tabular}

AD: Autosomal Dominant; AR: Autosomal Recessive; XLR: X-linked Recessive

cycles performed in 67 couples at risk for producing offspring with genetic predisposition to different cardiac diseases, caused by 23 genes, including 22 cycles for $\mathrm{CMD}, 32$ for $\mathrm{CMH}$ of all types, 10 for Long QT syndrome, 6 for Acyl-CoA dehydrogenase-very long-chain deficiency of ACADVLD, 8 for HoltOram syndrome, 8 for Noonan syndrome, 5 for cardio-encephalomyopathy, 2 for myopathy myofibrillar, 1-MFM1 and 1 for cardio skeletal myopathy. This is the largest series available for PGT for cardiac diseases, resulting in transfer of 123 predisposition free embryos in 89 cycles (1.38 average embryos per transfer), yielding 55 (61.7\%) clinical pregnancies and birth of 54 healthy children free of predisposing gene mutations and demonstrating the practical utility of PGT for this group of conditions.

As mentioned, the largest group of cardiac disorders for which PGT was performed was familial hypertrophic car- diomyopathy $(\mathrm{CMH})$, including patients with $\mathrm{CMH} 1, \mathrm{CMH} 2$, $\mathrm{CMH} 4, \mathrm{CMH} 7$ and $\mathrm{CMH} 8$, determined by mutation in $\mathrm{MYH7}$, TNNT2, MYBPC3, TNNI3 and MYL3 genes respectively. Neither of these couples had previous progeny but had a family history existed for premature or sudden death. Among them the most frequent was $\mathrm{HCM} 4$, caused by a mutation in the MYBPC3 gene, located on chromosome 11 (11p11.2) and encoding the cardiac isoform of myosin-binding protein $\mathrm{C}$. This is localized exclusively in heart muscle, with high risk of cardiac failure and sudden death. Of 22 PGT cycles performed for $\mathrm{CMH} 4$, a single most common in our experience, 23 embryos free of predisposing gene were detected for transfer in $16 \mathrm{cy}$ cles, resulting in birth of 9 children with no risk to develop cardiac disease in their lifespan.

Another most common cardiomyopathy for which PGT was performed was CMD1A, an autosomal-dominant disease 
Citation: Kuliev A, Pakhalchuk T, Prokhorovich M, et al. (2021) Preimplantation Genetic Testing for Inherited Predisposition to Cardiac Disease. Ann Heart 5(1):96-99

Table 2: List of Cardiac diseases and their causing mutations for which PGT was performed in our experience.

\begin{tabular}{|c|c|}
\hline Disease & Gene \\
\hline ACYL-COA DEHYDROGENASE, VERY LONG-CHAIN, DEFICIENCY OF; ACADVLD & $A C A D V L(A R)$ \\
\hline CARDIOENCEPHALOMYOPATHY, FATAL INFANTILE, DUE TO CYTOCHROME c OXIDASE DEFICIENCY 1; CEMCOX1 & $S C O 2(A R)$ \\
\hline CARDIOFACIOCUTANEOUS SYNDROME 4; CFC4 & MAP2K2 (AD) \\
\hline CARDIOMYOPATHY, DILATED, 1A; CMD1A & LMNA (AD) \\
\hline CARDIOMYOPATHY, DILATED, 1DD; CMD1DD & RBM20 (AD) \\
\hline CARDIOMYOPATHY, DILATED, 1E; CMD1E & SCN5A (AD) \\
\hline CARDIOMYOPATHY, DILATED, 1G; CMD1G & $\operatorname{TTN}(A D)$ \\
\hline CARDIOMYOPATHY, DILATED, WITH WOOLLY HAIR, KERATODERMA, AND TOOTH AGENESIS; DCWHKTA & $D S P(A D)$ \\
\hline CARDIOMYOPATHY, FAMILIAL HYPERTROPHIC, 1; CMH1 & $M Y H 7(A D)$ \\
\hline CARDIOMYOPATHY, FAMILIAL HYPERTROPHIC, 2; CMH2 & TNNT2 (AD) \\
\hline CARDIOMYOPATHY, FAMILIAL HYPERTROPHIC, 4; CMH4 & MYBPC3 (AD) \\
\hline CARDIOMYOPATHY, FAMILIAL HYPERTROPHIC, 7; CMH7 & $T N N I 3(A D)$ \\
\hline CARDIOMYOPATHY, FAMILIAL HYPERTROPHIC, 8; CMH8 & $M Y L 3(A D)$ \\
\hline CARDIOSKELETAL MYOPATHY WITH NEUTROPENIA AND ABNORMAL MITOCHONDRIA & $T A Z(X L R)$ \\
\hline COENZYME Q10 DEFICIENCY, PRIMARY, 7; COQ10D7 & COQ4 (AR) \\
\hline EMERY-DREIFUSS MUSCULAR DYSTROPHY 1, X-LINKED; EDMD1 & $E M D(X L R)$ \\
\hline HOLT-ORAM SYNDROME; HOS & $T B \times 5(A D)$ \\
\hline LOEYS-DIETZ SYNDROME 1; LDS1 & $T G F B R 2(A D)$ \\
\hline LONG QT SYNDROME 1; LQT1 & KCNQ1 (AD) \\
\hline LONG QT SYNDROME 2; LQT2 & $K C N H 2(A D)$ \\
\hline LONG QT SYNDROME 8; LQT8 & CACNA1C $(A D)$ \\
\hline MYOPATHY, MYOFIBRILLAR, 1; MFM1 & $D E S(A D)$ \\
\hline NOONAN SYNDROME 1; NS1 & PTPN11 (AD) \\
\hline TOTAL & 23 GENES \\
\hline
\end{tabular}

AD: Autosomal Dominant; AR: Autosomal Recessive; XLR: X-linked Recessive

caused by different mutations in the LMNA gene located on chromosome 1 . This cardiac disease is characterized by ventricular dilation and impaired systolic function, resulting in heart failure and arrhythmia that may cause premature or sudden death. While the large phenotypic variability of patients may be determined by different molecular mutations in the $L M N A$ gene, differences from one family to another may be also observed within the same mutation. Involvement of skeletal muscles may lead to muscle weakness.

As seen from Table 1, the list of Mendelian disorders for which PGT-M was performed now comprises 558 different conditions, with the most frequent ones shifting to common conditions with genetic predisposition, such as cancer, late-onset neurodegenerative conditions and cardiac disease. Risk of having offspring with severe late-onset common disorders of strong genetic predisposition is increasingly accepted indication for PGT-M. Spectrum of referral to PGT-M has also changed, with current shift to direct referral through expanded carrier screening [9]. Preference of PGT in contrast to prenatal diagnosis is explained by the fact that prenatal diagnosis could lead to pregnancy termination that was not considered well justified on the basis of genetic predisposition alone. That is, the tested fetus or embryo was not certain to become affected by cardiac disease. On the other hand, choosing the embryos free of genetic predisposition to disease for transfer would obviate the need for considering pregnancy termination, as only potentially normal pregnancies are established. PGT for such conditions gained acceptability on ethical grounds because only a limited number of the embryos (presently only one) is selected for transfer. The number of PGT requests for inherited predisposition for common late onset conditions has been increasing overall. One of the main reasons to request PGT for inherited cardiac diseases is that they often manifest despite pre-symptomatic diagnosis, and PGT may provide the only alternative for some at-risk couples to reproduce and avoid clinical termination of an affected fetus.

As in PGT for other common disorders, inherited cardiac disorder may not be realized throughout a patient's entire lifetime. This makes application of PGT for cardiac disease controversial, perhaps explaining still limited application of PGT for these conditions. The majority of inherited cardiac disorders is dominant, and without immediately applied care the first and sometimes the only clinical occurrence may be a premature or sudden death. No symptoms may be observed for years, and then provoked by factors such as excessive exercise. 
Among the conditions in the family history of the couples at risk that may indicate a possible need of PGT may be a heart attack and sudden death at young age, family members with pacemakers or internal cardiac defibrillators, arrhythmia, and cardiac surgery. The likelihood that offspring of these patients will develop the same heart disease will depend on the mode of inheritance, but penetrance is difficult to predict because many inherited cardiac conditions are difficult to diagnose, and will manifest at different ages. As mentioned, disease may also be induced by certain medications or activities such as excessive exercise that may lead to cardiac arrest or sudden death. All these justly requests for PGT-M. In some cases a common, apparently "milder" disease susceptibility gene may contribute to premature death, major disability, or hardship in a family. Personal experience may alter a family's perception of severity of the condition, and pivotal toward a decision to undertake PGT.

Because symptoms of inherited cardiac disease may be easily overlooked, findings in the family history may alone provide the reason to test for presence of predisposing gene mutations or the need for PGT. This may be a life-saving procedure for individuals at risk. With future advances in identification of genes predisposing to inherited cardiac disease, PGT might appear as a useful tool for couples at risk for producing offspring with inherited cardiac diseases that have high probability of premature or sudden death during their life span.

\section{References}

1. He J, McDermont DA, Song Y, et al. (2004) Preimplantation genetic diagnosis of human congenital heart disease and HoltOram syndrome. Am J Med Genet 126: 93-98.

2. Kuliev A, Pomerantseva E, Polling D, et al. (2012) PGD for inherited cardiac diseases. Reprod BioMed Online 24: 443-453.

3. Kuliev A, Pakhalchuk T, Rechitsky S (2015) Preimplantation genetic diagnosis for heart disease determined by genetic factors. Arrhythmia 1: 1.

4. Kuliev A, Rechitsky S, Simpson JL (2020) Practical preimplantation genetic testing. ( $3^{\text {rd }}$ edn) Springer Nature, Switzerland.

5. Kuliev A, Rechitsky S, Verlinsky O (2014) Atlas of preimplantation genetic diagnosis. An Illustrated Textbook. ( $3^{\text {rd }}$ edn), Taylor \& Francis, London.

6. Preimplantation Genetic Diagnosis International Society (PGDIS) (2008) Guidelines for good practice in PGD: Program requirements and laboratory quality assurance. Reprod BioMed Online 16: 134-147.

7. ESHRE PGT Consortium Steering Committee, Filipa C, Edith C, et al. (2020) ESHRE PGT consortium good practice recommendations for the organization of PGT. Human Reproduction Open, 2020.

8. Rechitsky S, Pakhalchuk T, Goodman A, et al. (2015) First systematic experience of combined PGD for single gene disorders and/ or Preimplantation HLA typing with 24-chromosome aneuploidy testing. Fertility \& Sterility 103: 503-512.

9. Simpson JL, Rechitsky S, Kuliev A (2019) Before the beginning: The genetic risk of a couple aiming to conceive. Fertil Steril 112: 622-630.

DOI: $10.36959 / 652 / 399$ 